\title{
GPS/INS Integrated Navigation System for Autonomous Robot
}

\author{
Tran Ngoc Huy ${ }^{1},{ }^{*}$, Le Manh Cam ${ }^{1}$, Nguyen Thanh Nam ${ }^{2}$
}

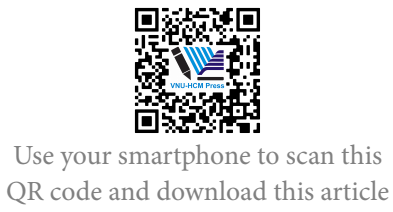

${ }^{1}$ Ho Chi Minh city University of

Technology, VNU-HCM

${ }^{2}$ National Key Laboratory of Digital Control and System Engineering, VNU-HCM

Correspondence

Tran Ngoc Huy, Ho Chi Minh city University of Technology, VNU-HCM

Email: tnhuy@hcmut.edu.vn

History

- Received: 15/10/2018

- Accepted: 25/12/2018

- Published: 31/12/2019

DOI : 10.32508/stdjet.v3iSI1.720

\section{Check for updates}

\section{Copyright}

(c) VNU-HCM Press. This is an openaccess article distributed under the terms of the Creative Commons Attribution 4.0 International license.

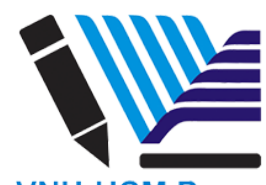

VNU-HCM Press

\begin{abstract}
Nowadays, autonomous robots are capable of replacing people with hard work or in dangerous environments, so this field is rapidly developing. One of the most important tasks in controlling these robots is to determine its current position. The Global Positioning System (GPS) was originally developed for military purposes but is now widely used for civilian purposes such as mapping, navigation for land vehicles, marine, etc. However, GPS has some disadvantages like the update rate is low or sometimes the satellites' signal is suspended. Another navigation system is the Inertial Navigation System (INS) can allow you to determine position, velocity and attitude from the subject's status, like acceleration and rotation rate. Essentially, INS is a dead-reckoning system so it has a huge cumulative error. An effective method is to integrate GPS with INS, in which the center is a nonlinear estimator (e.g. the Extended Kalman filter) to determine the navigation error, from which it can update the position the object more accurately. To improve even better accuracy, this paper proposes new method which combines the original integrated GPS/INS with tri-axis rotation angles estimation and velocity constraints. The experimental system is built on a low-cost IMU with tri-axis gyroscope, accelerometer and magnetometer and a GPS module to verify the model algorithm. Experiment results have shown that the rotation angles estimator helps us to determine the Euler angles correctly, thereby increasing the quality of the position and velocity estimation. In practice, the accuracy of roll and pitch angle is 2 degrees, the error of yaw angle is still large. The achieved horizontal accuracy is $2 \mathrm{~m}$ when the GPS signal is stable and $3 \mathrm{~m}$ when the GPS signal is lost in a short period. Compared with individual GPS, the error of the integrated system is about $10 \%$ smaller.
\end{abstract}

Key words: Autonomous Robot, GPS/INS Integration, IMU

\section{INTRODUCTION}

For autonomous robots (such as USV, UAV, AUV, etc.) to work in a stable and efficient manner, navigation is one of the most important issues to be aware of. The Global Positioning System (GPS) was originally developed for military purposes but is now widely used for civilian purposes such as mapping, navigation for land vehicles, marine, etc. However, GPS has some disadvantages like the update rate is low or sometimes the satellites' signal is suspended. Another navigation system is the Inertial Navigation System (INS) can allow you to determine position, velocity and attitude from the subject's status, like acceleration and rotation rate. Essentially, INS is a dead-reckoning system so it has a huge cumulative error. An effective method is to integrate GPS with INS, in which the center is a nonlinear estimator (e.g. the Extended Kalman filter) to determine the navigation error, from which it can update the position the object more accurately ${ }^{1}$.

Depending on the "depth" of the interaction and for the shared information between the GPS and INS, we have some integration methods: uncoupled integration, loosely coupled (LC), tightly coupled (TC) and deeply integrated ${ }^{2}$. For uncoupled method, GPS output is used as the "reset" signal for the INS. When there is no GPS solution (position and velocity), the integrated system uses INS to estimate. This method has the simplest structure, but the system cannot estimate the sensor's drift, so it is not commonly used. In LC method, GPS solutions will be compared with the inertial estimation in order to calculate the error state of the object ${ }^{3,4}$. In TC method the integration is "deeper", the raw measurements of the GPS (pseudorange and Doppler measurements) are directly combined with the calculated INS estimation results in an appropriate filter ${ }^{4,5}$. Both LC and TC systems operate in closed loop, i.e. position, velocity, attitude errors and sensor's drifts are fed back for the INS and GPS to make a navigation correction. The loosely coupled model is simpler than the tightly one. The structure of tightly coupled model and deeply integration are very complex, so we do not mention in this paper. In estimating Euler angles, conventional INS systems use tri-axis angular rate to calculate these angles. However, MEMS (Micro-Electro-Mechanical 
Systems) IMUs often have large disturbances, so their errors often accumulate rapidly. The INS mechanization method for update rotation angles is only available for a short period. In this paper we use a triangular Euler angles estimator. The centerpiece of this estimator is the two-stage Extended Kalman filter, using accelerometer and magnetic field values to correct the angles evaluated using rotation rate ${ }^{6}$.

This paper introduces the building method of loosely coupled GPS/INS integrated navigation system. The Euler angles estimation and the velocity constraints are used to improve accuracy. We use MAT$\mathrm{LAB} /$ Simulink software to simulate and analyze data. The experimental system is built on a low-cost IMU with tri-axis gyroscope, accelerometer and magnetometer and a GPS module to verify the model algorithm. The update rate of the integrated system is equal to the INS rate of $100 \mathrm{~Hz}$ and the rate of GPS is $10 \mathrm{~Hz}$. The data acquisition and processing system is performed on an ARM Cortex-M4 microcontroller.

\section{METHODOLOGY}

\section{Inertial navigation system}

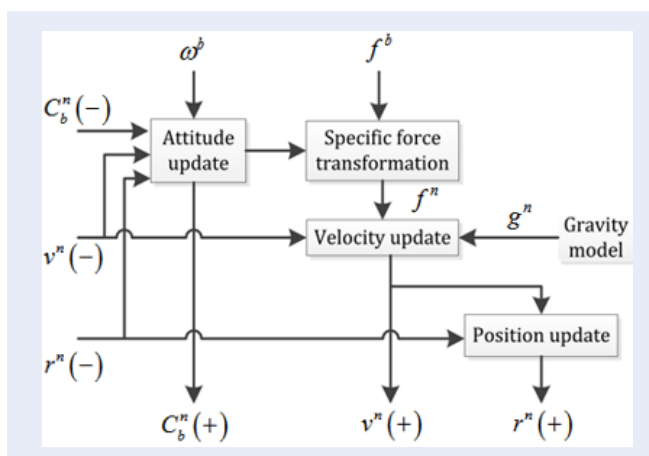

Figure 1: INS mechanization in NED frame.

INS is a navigation system that uses tri-axis inertial sensors (gyroscope, accelerometer and magnetometer) to calculate the orientation and position of an object. This system does not need an external reference, so it can continuously calculate without interruption. In this paper, outputs of inertial sensors are three components of the gyroscope, three components of the accelerometer and three components of the magnetometer in the body-frame, denoted by $f^{b}, \omega^{b}, m^{b}$ respectively. The Figure 1 describes the INS mechanization in NED frame ${ }^{3}$. The INS uses rotation rate and acceleration values from the IMU sensor to update attitude, velocity and position by the following formula:

$$
\left[\begin{array}{c}
\dot{r}^{n} \\
\dot{v}^{n} \\
\dot{C}_{b}^{n}
\end{array}\right]=\left[\begin{array}{c}
D^{-1} \cdot v^{n} \\
C_{b}^{n} \cdot f^{b}+g^{n}-\left(2 \omega_{i e}^{n}+\omega_{e n}^{n}\right) \cdot v^{n} \\
C_{b}^{n} \cdot\left(\Omega_{i b}^{b}-\Omega_{i n}^{b}\right)
\end{array}\right]
$$

In this formula, vector $r^{n}=\left[\begin{array}{lll}\varphi & \lambda & h\end{array}\right]^{T}$ is the position vector, whose components are geographic latitude, longitude and altitude (height) respectively. Vector $\mathrm{v}^{n}$ is the velocity vector in NED coordinate. Matrix $C_{b}^{n}$ is the direction cosine matrix (DCM, or rotation matrix) from body-frame to NED frame. The symbols $\omega$ and $\Omega$ denote the angular rate and its skew symmetric form, matrix $\mathrm{D}$ is the transition matrix from NED frame to latitude, longitude and altitude:

$D=\left[\begin{array}{ccc}M+h & 0 & 0 \\ 0 & (N+h) \cdot \cos \varphi & 0 \\ 0 & 0 & -1\end{array}\right]$

Formula (1) is written in continuous form. In experiment, we have to discretize it for simplicity in calculation. Because of this discretization, the update process always has error. On the other hand, IMU sensor has other types of error like bias and scale factor. Thus, the INS errors are rapidly accumulating. To improve the accuracy of the navigation estimation, we use a tri-axis Euler angles estimator ${ }^{6}$. It is structured as a two-stage cascaded Extended Kalman filter (Figure 2). These filters use acceleration and magnetic field measured from the IMU to correct the Euler angles (roll, pitch and yaw). Precisely, first the EKF-1 combines the gyroscope and accelerometer measurements to calculate the Earth's gravity vector in NED frame, and then it can determine roll and pitch angles. Next, the EKF-2 uses the gyroscope, magnetic field measurements and the determined roll and pitch to calculate yaw angle. In experimental conditions, the accuracy of roll and pitch is 1 degree and accuracy of yaw angle is 3 degrees.

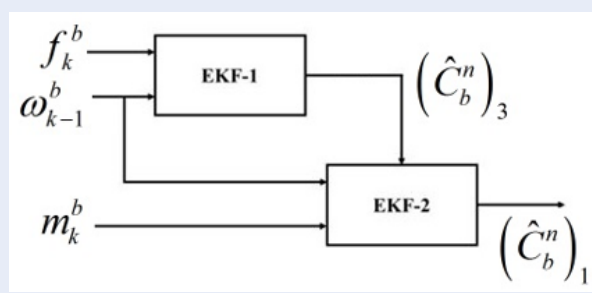

Figure 2: Diagramof the rotation angle estimation.

Rotation rate and acceleration measurements can be affected by noises such as deviation, scale factor, nonorthogonality and some other types. Some types of error can be identified and calibrated in the laboratory environment. Some types are unpredictable, and 
have to be modeled as random noise. In the above factors, bias has the greatest effect on the measurement value of the IMU. So we can model the remaining types of noise (except bias) as white noise (denoted by the symbol $\eta$ ), we have the estimation equation: $\left\{\begin{array}{l}\widehat{f}=\widetilde{f}-b_{a}+\eta_{a} \\ \widehat{\omega}=\widetilde{\omega}-b_{g}+\eta_{g}\end{array}\right.$

In (3), the symbols $\widehat{f}$ and $\widehat{\omega}$ are estimated values of acceleration and angular velocity, $\widetilde{f}$ and $\widetilde{\omega}$ are values measured from the IMU sensor, the symbol b is the bias and $\eta$ is the other types of noise (modeled as white noise).

\section{Loosely Coupled scheme}

The loosely coupled model also referred to as "decentralized" filtering, consists of two estimators. The first one is a nonlinear estimator. It combines the INS estimation results with the GPS results to estimate the position, velocity, attitude error and the IMU sensor's error. The second is the GPS filter. It uses the pseudorange and Doppler measurement values from GPS module to determine the position, velocity. Figure 3 shows the diagram of loosely coupled model.

In today's GPS modules, there is usually a built-in GPS data processor, which can calculate position, velocity and some other information from GPS raw data. In the LC model, position and velocity are fed into the nonlinear filter. The filter used in this paper is the Extended Kalman filter, which is suitable for nonlinear systems. Measurement values from IMU sensor (angular rate and acceleration) after being computed using the Euler angles estimation and INS mechanization, will be compared with the position and velocity of the GPS. The difference between two results is used as the input of the EKF. The integrated system works in closed loop, the estimated error values are fed back to adjust the state of the INS system and to compensate for the IMU measurements. This closeloop model is suitable for MEMS IMU, which has large disturbance.

The error state vector $\delta x$ of the EKF filter in this model is composed of the position error $\delta r^{n}$, the velocity error $\delta v^{n}$, the attitude error $\varepsilon$, the acceleration bias error $\delta b_{a}$ and the gyroscope bias error $\delta b_{g}$. Derive the INS mechanization function and take the first order elements $^{3}$, we have the process model equation:

$\delta \dot{x}=F . \delta x+G . u$

where:

$F=\left[\begin{array}{ccccc}F_{r r} & F_{r v} & 0_{3 \times 3} & 0_{3 \times 3} & 0_{3 \times 3} \\ F_{v r} & F_{v v} & \left(f^{n} x\right) & C_{b}^{n} & 0_{3 \times 3} \\ F_{e r} & R_{e v} & -\left(\omega_{i n}^{n} x\right) & 0_{3 \times 3} & -C_{b}^{n} \\ 0_{3 \times 3} & 0_{3 \times 3} & 0_{3 \times 3} & -1 / \tau_{b a} & 0_{3 \times 3} \\ 0_{3 \times 3} & 0_{3 \times 3} & 0_{3 \times 3} & 0_{3 \times 3} & -1 / \tau_{b g}\end{array}\right]$
$G=\left[\begin{array}{cccc}0_{3 \times 3} & 0_{3 \times 3} & 0_{3 \times 3} & 0_{3 \times 3} \\ C_{b}^{n} & 0_{3 \times 3} & 0_{3 \times 3} & 0_{3 \times 3} \\ 0_{3 \times 3} & -C_{b}^{n} & 0_{3 \times 3} & 0_{3 \times 3} \\ 0_{3 \times 3} & 0_{3 \times 3} & I_{3 \times 3} & 0_{3 \times 3} \\ 0_{3 \times 3} & 0_{3 \times 3} & 0_{3 \times 3} & I_{3 \times 3}\end{array}\right]$

In matrix $F, \tau_{b a}$ and $\tau_{b g}$ are the correlation time vectors of accelerometers and gyroscopes, determined based on the Gauss-Markov model. The components of vector $\mathrm{u}$ are white noises, with the covariance determined by the formula:

$Q=\operatorname{diag}\left(\left[\begin{array}{llll}q_{a} & q_{g} & q_{b a} & q_{b g}\end{array}\right]\right), q=\frac{2 \sigma^{2}}{\tau}$

In the above formula, $\sigma$ is the standard deviation of the Gauss-Markov noise. Matrix Q is called the spectral density matrix and its component, respectively, are covariance accelerometer, gyroscope, accelerometer bias and gyroscope bias. These values can be determined in the datasheet of the sensor ${ }^{5}$.

The measurement model of the EKF is the difference of the INS results (position and velocity) and GPS results:

$\delta z=\left[\begin{array}{ll}r_{I N S}^{n} & -r_{G P S}^{n} \\ v_{I N S}^{n} & -v_{G P S}^{n}\end{array}\right]=H . \delta x+\varepsilon$

In the above equation, symbol $\varepsilon$ is the measurement noise. Its covariance matrix $\mathrm{R}$ can be obtained from GPS processing. The activation of the EKF is divided into 2 stages: update and prediction. The Kalman gain is computed first in the update stage. Then state variables $(\delta x)$ and error covariance $(\mathrm{P})$ are updated based on prior estimates and its error covariance. After each correction, the error state vector should be reset to zero.

When there is a GPS outage, we can use velocity constraints (Figure 4) to estimate errors ${ }^{4}$. Vehicles essentially move in forward direction. If the vehicle does not jump off the ground nor slide on the ground, its velocity in the axes perpendicular to the forward direction (y-axis and $z$-axis) is almost zero. So we have two velocity constraints:

$\left\{\begin{array}{l}v_{y}^{b} \approx 0 \\ v_{z}^{b} \approx 0\end{array}\right.$

\section{SIMULATION RESULTS}

In simulation, we use FlightGear simulation software $^{7}$ to create the data file and use MATLAB/Simulink to process it. The GPS signal is disturbed with noise to research about noise suppression of the estimator. The standard deviation of noise is $2.5 \mathrm{~m}$ in each horizontal axis and $5 \mathrm{~m}$ in vertical axis. Simulations were made in two cases: with and without the Euler angles estimator. We have the (rosult Table 1:

From the above table, we can see that with the rotation angles estimator, the results are better. The horizontal 


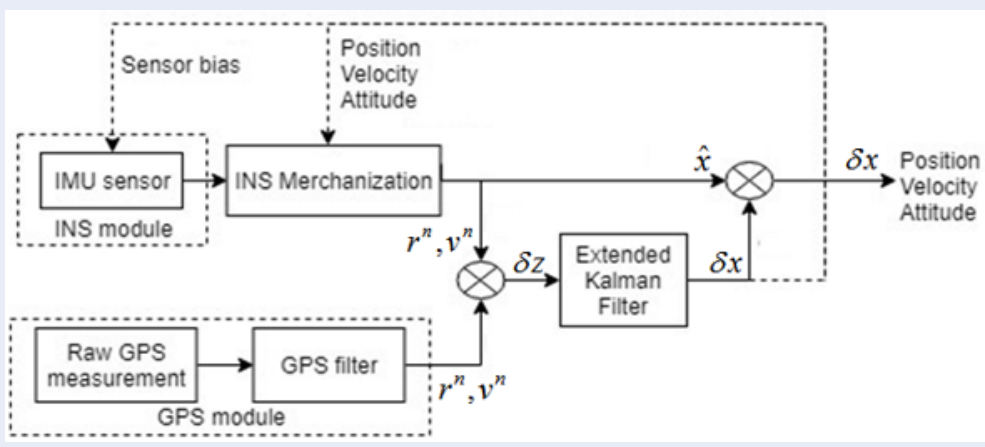

Figure 3: Loosely-coupled model with 15 -state vector.

Table 1: Attitude, position and velocity errors

\begin{tabular}{|c|c|c|c|c|c|c|}
\hline Error & \multicolumn{3}{|c|}{ Without Euler angles estimation } & \multicolumn{3}{|c|}{ With Euler angles estimation } \\
\hline $\begin{array}{l}\text { Attitude } \\
\text { (r-p-y) } \\
\text { (degree) }\end{array}$ & 24.7 & 48.6 & 14.8 & 2.0 & 2.0 & 2.0 \\
\hline $\begin{array}{l}\text { Position } \\
\text { NED (m) }\end{array}$ & 0.69 & 1.54 & 1.62 & 0.43 & 0.47 & 2.99 \\
\hline $\begin{array}{l}\text { Velocity } \\
\text { NED (m/s) }\end{array}$ & 1.80 & 3.46 & 4.61 & 0.05 & 0.05 & 0.04 \\
\hline
\end{tabular}

accuracy is about 0.64 meters. The velocity error is within $0.1 \mathrm{~m} / \mathrm{s}$. We can conclude that the estimator has good filtering capability. Next, we will examine the quality of the system when the GPS signal is lost in intervals of 3,5 and 10 seconds.

From Table 2, we can conclude that when there is a GPS outage, the error of the system will be larger than the normal case (GPS fix). In addition, if the GPS lost time is longer, the horizontal error is larger. Using an Euler angles estimator helps to make smaller errors.

\section{EXPERIMENTAL RESULTS AND DISCUSSION}

\section{Hardware development}

We built an experimental system to verify the implemented algorithm. The hardware (Figure 5) consists of the IMU sensor ADIS16405 from Analog Devices ${ }^{8}$, the GPS module from U-blox ${ }^{9}$ and the microcontroller STM32F407 (ARM Cortex-M4) from STMicroelectronics ${ }^{10}$.

The reference system is the GNSS/INS system from Xsens Technology. The MTi-G-700 ${ }^{11}$ can give rotation angles estimate with a 1degree accuracy, position error of 2 meters and velocity error of $0.05 \mathrm{~m} / \mathrm{s}$.

The update rate of INS and GPS are $100 \mathrm{~Hz}$ and 10 $\mathrm{Hz}$, respectively. In each INS cycle of 10 milliseconds, the STM32F407 microcontroller reads data from the IMU sensor and the GPS module. Then update the error estimator, using Extended Kalman filter algorithm. Navigation data is sent to the computer via COM/RS232 port or via SD card.

\section{Results}

For MEMS IMU sensors, the amplitude of its noise is huge, so if we do not use the Euler angles estimator, the result is bad, the attitude, position, velocity errors are enormous. The estimated trajectory (red dots in Figure 6) does not have the same shape with the reference one (black line). In contrast, when we use the angles estimator, the errors are smaller, the accuracy is higher. The horizontal error of our GPS/INS system is $1.69 \mathrm{~m}$, while the error of the individual GPS system is $1.93 \mathrm{~m}$. For this reason, the GPS/INS algorithm can reduce over $10 \%$ of the error. On the other hand, the update rate of GPS is only $10 \mathrm{~Hz}$. The integrated GPS/INS update rate is 10 times larger (100 $\mathrm{Hz}$ ). We can see the effective of high update rate in Figure 6. Because the GPS has the low update rate of $10 \mathrm{~Hz}$, there are visible spaces between the green dots (GPS-only). And if the vehicle moves very fast, the GPS cannot describe the vehicle's trajectory accurately. Differently, the blue dots (GPS/INS) approx- 


\section{Table 2: Horizontal accuracy during GPS outages}

\begin{tabular}{lll}
\hline GPS outage & Without Euler angles estimation & With Euler angles estimation \\
3 seconds & $15.0 \mathrm{~m}$ & $0.88 \mathrm{~m}$ \\
5 seconds & $35.8 \mathrm{~m}$ & $0.92 \mathrm{~m}$ \\
10 seconds & $171.4 \mathrm{~m}$ & $1.33 \mathrm{~m}$ \\
\hline
\end{tabular}

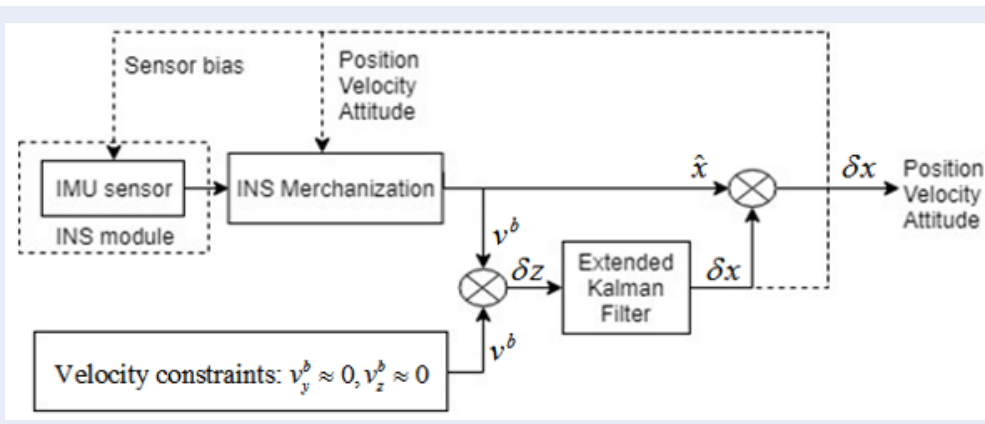

Figure 4: EKF with velocity constraints.

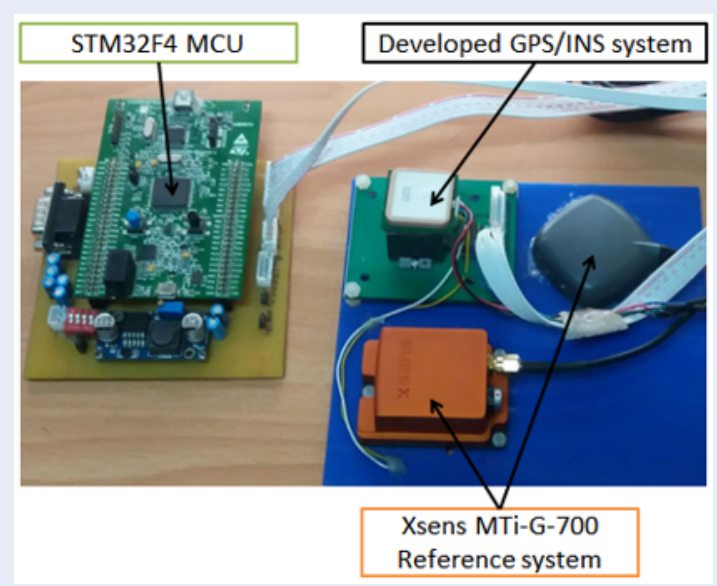

Figure 5: GPS/INS system in experiments.

Table 3: Attitude, position and velocity errors

\begin{tabular}{|c|c|c|c|c|c|c|}
\hline Error & \multicolumn{3}{|c|}{ Without Euler angles estimation } & \multicolumn{3}{|c|}{ With Euler angles estimation } \\
\hline $\begin{array}{l}\text { Attitude } \\
\text { (r-p-y) } \\
\text { (degree) }\end{array}$ & 70 & 29 & 83 & 1.31 & 1.07 & 16.7 \\
\hline $\begin{array}{l}\text { Position } \\
\text { NED (m) }\end{array}$ & 11 & 7.7 & 313 & 1.58 & 0.58 & 4.42 \\
\hline $\begin{array}{l}\text { Velocity } \\
\text { NED (m/s) }\end{array}$ & 10 & 6.4 & 85 & 0.27 & 0.26 & 0.46 \\
\hline
\end{tabular}




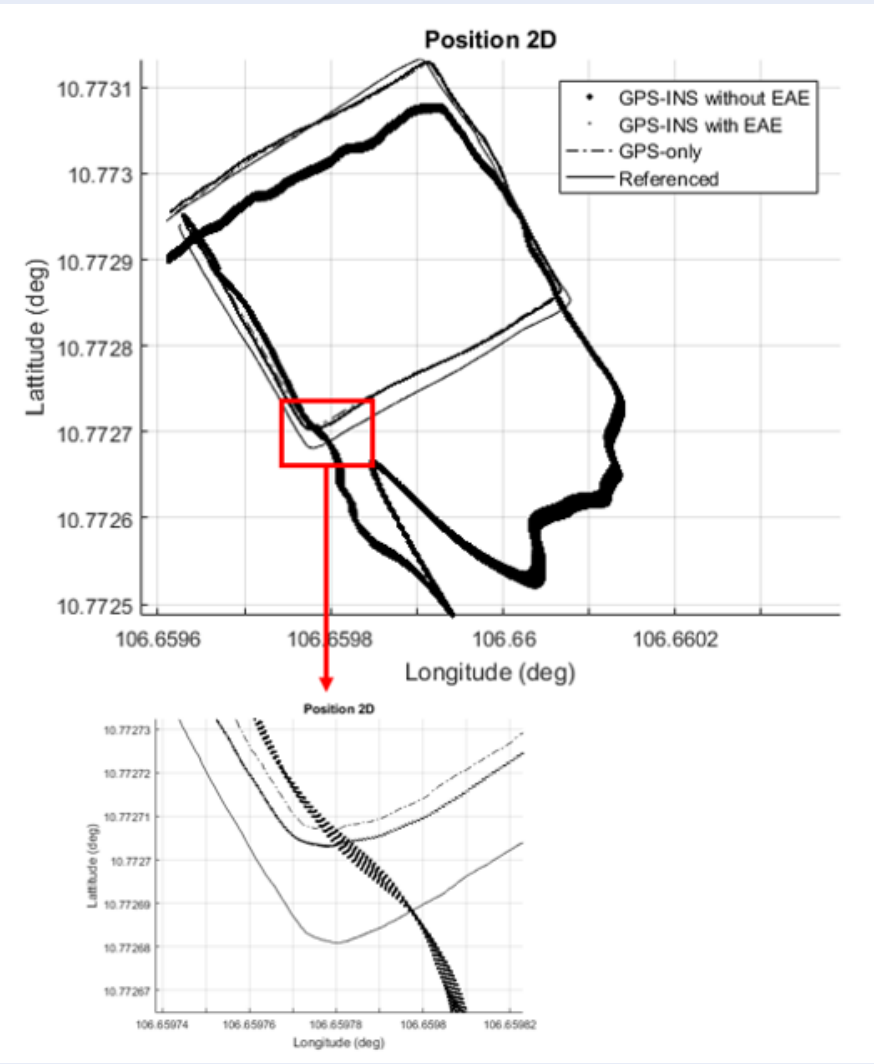

Figure 6: Estimated 2D position.

imately form a continuous line. From the above results, it can be concluded that the angles estimator can improve the accuracy of the navigation system and the integrated GPS/INS system performs better than the single GPS system (Table 3).

Next, assuming the GPS signal is lost for a period of 5 seconds, we will analyze the accuracy of implemented GPS/INS system in cases with and without speed constraints. We will simulate GPS outages in two cases: GPS lost in straight line and in curved line (Table 4). From the above results, we can see in the normal case of GPS fix, the velocity constraints can still reduce the horizontal error of the system. When there is a GPS outage, using speed constraints can either increase or decrease the system's accuracy. However, it restricts the trajectory from divergence. The blue dots in Figures 7 and 8 can follow the reference trajectory, while the red dots are diverging. Thus, velocity constraints are also a tool that can improve the accuracy of the integrated GPS/INS navigation system.

\section{CONCLUSIONS}

In this paper, we have implemented a loosely coupled GPS/INS integrated navigation system. The main al- gorithm in this system is the Extended Kalman filter. We combined the EKF with Euler angles estimator and velocity constraints to improve accuracy.

The rotation angles estimator helps us to determine the Euler angles correctly, thereby increasing the quality of the position and velocity estimation. In practice, the accuracy of roll and pitch angle is 2 degrees, the error of yaw angle is still large.

The achieved horizontal accuracy is $2 \mathrm{~m}$ when the GPS signal is stable and $3 \mathrm{~m}$ when the GPS signal is lost in a short period. Compared with individual GPS, the error of the integrated system is about $10 \%$ smaller. In addition, the positive point of the GPS/INS is its update rate reaches $100 \mathrm{~Hz}$, which is 10 times larger than the initial system. When there is a long-period GPS outage, the LC algorithm's result is very bad, so we need to use the tightly coupled model. In the future, we will research about this model, point out its advantages and disadvantages, and compare with the original model. After that, we will find the optimal switching method between two models. 
Table 4: Horizontal accuracy when GPS lost, with and without velocity constraints

\begin{tabular}{|c|c|c|c|}
\hline & \multicolumn{3}{|c|}{ Horizontal error (m) } \\
\hline & GPS fix & $\begin{array}{c}5 \text { seconds GPS lost, } \\
\text { straight line }\end{array}$ & $\begin{array}{c}5 \text { seconds GPS lost, curved } \\
\text { line }\end{array}$ \\
\hline $\begin{array}{l}\text { Without velocity con- } \\
\text { straints }\end{array}$ & 1.69 & 2.23 & 2.60 \\
\hline $\begin{array}{l}\text { With velocity con- } \\
\text { straints }\end{array}$ & 1.59 & 2.76 & 1.96 \\
\hline
\end{tabular}

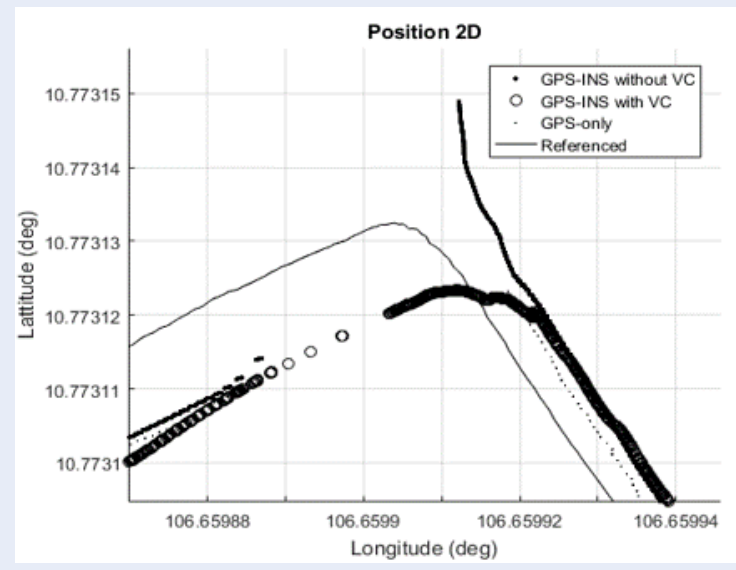

Figure 7: GPS outage - straight line.

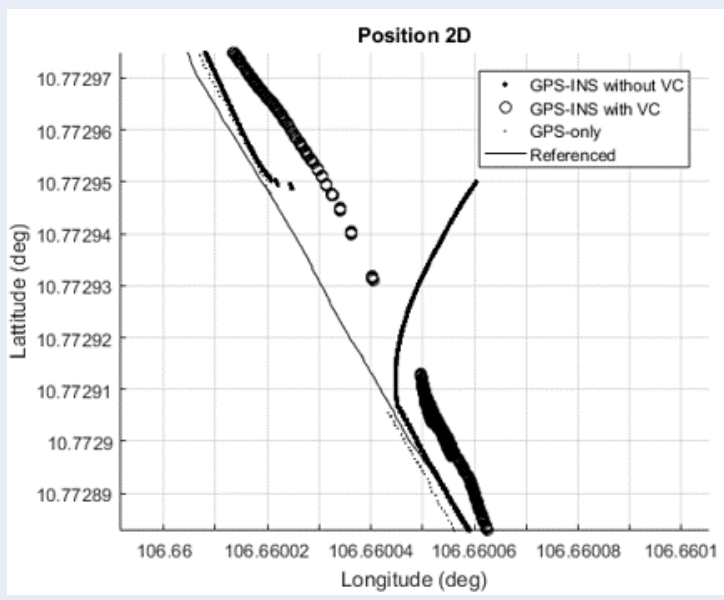

Figure 8: GPS outage - Curved line. 


\section{ACKNOWLEDGEMENT}

This research is supported by National Key Laboratory of Digital Control and System Engineering (DCSELAB), HCMUT and funded by Vietnam National University Ho Chi Minh city (VNU-HCM) under grant number C2018-20b-02.

\section{CONFLICT OF INTERESTS}

The author declares that this paper has no conflict of interests.

\section{AUTHORS' CONTRIBUTIONS}

Tran Ngoc Huy has developed the proposed algorithm and wrote the manuscript. Le Manh Cam and Nguyen Thanh Nam implemented simulation, experiment and wrote the manuscript.

\section{ABBREVIATIONS}

USV: Unmanned Surface Vehicle UAV: Unmanned Aerial Vehicle

AUV: Autonomous Underwater Vehicle

GPS: Global Positioning System

INS: Inertial Navigation System
LC: Loosely Coupled

TC: Tightly Coupled

EKF: Extended Kalman Filter

\section{REFERENCES}

1. Kim K. GPS/INS with non-linear filters. ICCAS 2011, KINTEX, Gyeonggi-do, Korea. 2011;

2. Schmidt GT, Phillips RE. INS/GPS Integration Architectures. RTO Lecture Series RTO-EN-SET-1 16. 2010;.

3. Shin EH. Accuracy Improvement of Low Cost INS/GPS for Land Applications. University of Calgary. 2001;

4. Angrisano A. GNSS/INS Integration Methods. PhD Thesis, The Parthenope University of Naples, Italy. 2010;

5. Nguyen HD, et al. Implementation of a GPS/INS tightlycoupled system in urban environment. The 3rd Vietnam Conference on Control and Automation, Ho Chi Minh city. 2015;.

6. Tran NH, Le MC. Orientation estimation using extended Kalman filter. The 4th Conference on Science and Technology, HCMC University of Transport. 2018;.

7. FlightGear Flight Simulator ;Available from: http://home. flightgear.org/.

8. Analog Devices. ADIS16405 - Triaxial Inertial Sensor with Magnetometer. 2017;

9. u-blox AG. NEO-M8, u-blox M8 concurrent GNSS modules. 2016;

10. STMicroelectronics, Datasheet STM32F405xx - STM32F407xx 2016;

11. Xsens Technologies, MTi User Manual: MTi 10-series and MTi 100-series 5th generation. 2018;. 


\title{
Xây dựng hệ thống định vị tích hợp GPS/INS cho robot tự hành
}

\author{
Trần Ngọc Huy ${ }^{1}$, , Lê Mạnh Cầm ${ }^{1}$, Nguyễn Thanh Nam²
}

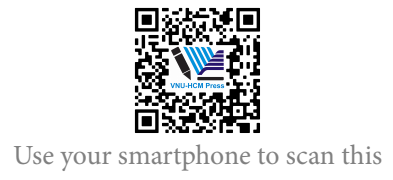

QR code and download this article

\section{TÓM TẮT}

Các loại robot tự hành có khả năng thay thế con người làm những công việc nặng nhọc, ở những môi trường khó khăn, nguy hiểm, vì vậy lĩnh vực này hiện đang rất phát triển. Một trong những vấn đề quan trọng trong việc điều khiển các loại robot tự hành đó là xác định vị trí hiện tại của robot. Hẹ thống định vị toàn cầu (GPS) được sử dụng rộng rãi trong lĩnh vực này, tuy nhiên có một số nhược điểm như tốc độ cập nhật thấp hoặc đôi khi mất tín hiệu từ các vệ tinh. Một hệ thống điều hướng khác là Hệ thống dẫn đường quán tính (INS) có thể cho phép ta xác định vị trí, vận tốc và góc xoay của robot. Tuy nhiên, INS khi tính toán sẽ làm sai số tích lũy theo thời gian. Một phương pháp hiệu quả là tích hợp GPS với INS, trong đó trái tim của hệ thống là công cụ ước tính phi tuyến (ví du: bộ loc Kalman mở rộng) từ đó có thể khắc phuc được khuyết điểm của hệ thống GPS và INS so với khi tích hợp riêng rẽ. Bài báo này giới thiệu về phương pháp tích hợp lỏng GPS/INS, sử dụng bô ước lương góc xoay ba truc và ràng buộc vân tốc để cải thiện độ chính xác. Giải thuâat được thức nghiệm kiểm chứng trên cảm biến quán tính giá rẻ gồm con quay hồi chuyển, cảm biến gia tốc, từ trường ba trục và cảm biến GPS. Kết quả cho thấy sai số của góc roll và pitch là 2 độ, sai số của góc yaw vẫn còn lớn. Độ chính xác theo phương ngang đạt được là $2 m$ khi tín hiệu GPS ổn định và $3 \mathrm{~m}$ khi tín hiệu GPS bị mất trong một khoảng thời gian ngắn. So với hệ thống GPS riêng lẻ, sai số của hệ thống tích hợp nhỏ hơn khoảng 10\%.

Từ khoá: Robot tự hành, Tích hợp định vị/hệ thống định vị quán tính, thiết bị đo lường quán tính

\section{${ }^{1}$ Trường Đại học Bách khoa,} ĐHQG-HCM

${ }^{2}$ Phòng Thí nghiệm Trọng điểm Điều khiên số và Kỹ thuật Hệ thống, ĐHQG-HCM

\section{Liên hệ}

Trần Ngọc Huy, Trường Đại học Bách khoa, ĐHQG-HCM

Email: tnhuy@hcmut.edu.vn

Lịch sử

- Ngày nhận: 15/10/2018

- Ngày chấp nhận: 25/12/2018

- Ngày đăng: 31/12/2019

DOI : 10.32508/stdjet.v3iSI1.720

\section{Check for updates}

\section{Bản quyền}

(c) ĐHQG Tp.HCM. Đây là bài báo công bố mở được phát hành theo các điều khoản của the Creative Commons Attribution 4.0 International license.

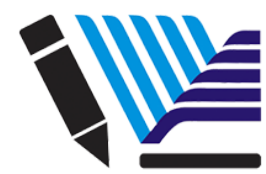

VNU-HCM Press
Trích dẫn bài báo này: Huy $\mathrm{T} N$, Cầm $L \mathrm{M}, \operatorname{Nam} \mathrm{N}$ T. Xây dựng hệ thống định vị tích hợp GPS/INS cho robot tự hành. Sci. Tech. Dev. J. - Eng. Tech.; 2(SI1):SI29-SI37. 